\title{
Supplementation with Silk Amino Acids improves physiological parameters defining stamina in elite fin-swimmers
}

\author{
Igor Z Zubrzycki ${ }^{1,3^{*}}$, Zbigniew Ossowski $^{1 \dagger}$, Stanislaw Przybylski ${ }^{1}$, Magdalena Wiacek ${ }^{1}$ Anna Clarke ${ }^{2}$
} and Bartosz Trabka'

\begin{abstract}
Background: Previous animal study has shown that supplementation with silk amino acid hydrolysate (SAA) increases stamina in mice. The presented study was the first formal evaluation of the influence of SAA supplementation on parameters defining physiological fitness level in humans.

Methods: It was a randomized controlled trial with a parallel-group design on elite male fin-swimmers. The experimental group was supplemented with $500 \mathrm{mg}$ of SAA per $\mathrm{kg}$ of body mass, dissolved in $250 \mathrm{ml}$ of a Carborade Drink $^{\oplus}$; the control group with Carborade Drink ${ }^{\circledast}$ alone; 3 times a day, 30 minutes prior to the training session.

Results: Changes discerned in the experimental group were more pronounced than those observed in the control group. For example, the change in the serum lactic acid concentration observed in the experimental group was sevenfold less than in the control group [ 21.8 vs. $-3.7 \mathrm{~L} \%$ for the control and experimental groups, respectively]. An analysis of a lactate profile as a function of a maximal swimming velocity exposed a statistically significant positive shift in the swimming velocity of $0.05 \mathrm{~m} / \mathrm{s}$, at the lactate concentration of $4 \mathrm{mmol} / \mathrm{L}$ in the experimental group. There was also a positive, although statistically insignificant, increase of $2.6 \mathrm{~L} \%$ in serum testosterone levels in the experimental group.

Conclusions: This study showed that a 12-day SAA supplementation combined with an extensive and rigorous training schedule was sufficient to increase an aerobic stamina. However, this phenomenon was associated with an augmented level of muscular damage (an increased level of creatine phosphokinase in the experimental group).
\end{abstract}

Keywords: Silk amino acids, Stamina, Testosterone, Human

\section{Introduction}

A shorter running time, a longer jump, or a longer distance run during a specific time, are results of not only a rigorous training regime but also of an increase of understanding of human physiology combined with modern nutritional techniques.

Recently, a hydrolysate of silk amino acids (SAA) from silk of silkworms (Bombyx mori) comprising of peptides of a length of 18 to 19 amino acids, has become very

\footnotetext{
* Correspondence: igorzubrzycki@yahoo.com

${ }^{\dagger}$ Equal contributors

'Jędrzej Śniadecki Academy of Physical Education and Sport ul, Kazimierza Górskiego 1, Gdańsk 80-336, Poland

${ }^{3}$ School of Health and Applied Sciences, Polytechnic of Namibia, Private Bag 13388, 13 Storch Street, Windhoek, Namibia

Full list of author information is available at the end of the article
}

popular among people performing leisure and competition sports.

According to a variety of findings employing animal models, SAA exerts a vista of physiological actions including, among others, anti-diabetic [1], anti-oxidant [2], and anti-tumor [3] properties. One study had even shown that SAA may also influence levels of blood triglycerides [4].

Although some study indicated that branched-chain amino acids (BCAA) supplementation $(300 \mathrm{mg} / \mathrm{kg}$ of body mas/day) may enhance exercise capacity [5] recent studies on an animal model, performed by South Korean scientists, showed that high doses of SAA, i.e., $800 \mathrm{mg} / \mathrm{kg}$ of body-mass [6] or $500 \mathrm{mg} / \mathrm{kg}$ [7] also enhance stamina.

\section{() Biomed Central}


The latter also shows a clear augmentation of testosterone production.

Although, as stated above, SAA and BCAA evoke similar physiological response, i.e., enhancement of exercise capacity, the obvious differences in their amino acid compositions - BCAA comprises of Leu, Ile, and Val whereas SAA: Ala, Gly, Ser, Val, and Thr - enforces, most probably, different modes of their metabolic action. It is known that BCAAs are mainly oxidized in skeletal muscle and that exercises promote oxidation of BCAA [8]. The mode of action of SAA is currently not established, although there are some indications that its oxidation will occur mainly in liver and the main amino acid, playing the paramount role in its physiological function, is L-alanine -through its conversion to beta-alanine [9].

Since SAA is already on shelves of many sport nutrition shops, we undertook the task of verifying its staminaenhancing viability on a human model. The presented study was a randomized controlled trial with a parallelgroup design on male competitive fin-swimmers.

\section{Methods \\ Ethics}

All procedures used in this study were in accordance with the ethical standards of the regional medical chamber. A written consent was obtained in writing from participants and/or guardians of participants under the age of 18 years.

\section{Study subjects}

We conducted a randomized controlled trial with a parallel-group design of competitive male fin-swimmers. All participants were recruited from the national finswimmer team.

Both samples' size was eight (i.e., the control and the experimental sample), and the age means and standard deviations were $17.6 \pm 3.78$ and $20.71 \pm 4.82$, respectively.

\section{Training program}

The training camp, during which the experiment was performed, was a microcycle lasting 12 days and comprising three training units daily: (1) 7:00-9:30 am swimming, (2) 11:00-1:00 pm walking and/or running, every other day stretching, and (3) 3:00-5:00 pm swimming.

Within this microcycle, each of the competitors performed 30 training units constituting of total 65training hours. Each of the subjects swam, on average, $7 \mathrm{~km}$ per day.

\section{Supplementation}

All the required supplements were bought directly from a distributor (Fitness Authority ${ }^{\circ}$, http://www.fanutrition. $\mathrm{pl} / \mathrm{en}$ ) without an indication of the purpose of the purchase. According to the producer, the supplement contained $85.95 \mathrm{~g}$ of SAA (alanine, glycine, serine, valine, and threonine) per $100 \mathrm{~g}$ of dry mass. A required daily amount of SAA, comprising total of $500 \mathrm{mg}$ SAA per $\mathrm{kg}$ of body mass, was dissolved in $250 \mathrm{ml}$ of a Carborade Drink $^{\bullet}$ containing $6.3 \mathrm{~g}$ of carbohydrates, $0.046 \mathrm{~g}$ of sodium, $2.4 \mathrm{mg}$ of niacin, $1.8 \mathrm{mg}$ Vitamin E, $0.9 \mathrm{~g}$ pantothenic acid, $0.21 \mathrm{~g}$ Vitamin B6, and $7.5 \mu \mathrm{g}$ of Biotin per $750 \mathrm{ml}$. A respective nutrition, i.e., a mixture of SAA and Carborade Drink ${ }^{\ominus}$, and Carborade Drink ${ }^{\circ}$ alone was served through a straw in lidded cups to both the experimental and the control groups three times a day 30 minutes before each training session [10]. It has to be stressed that all drinks were prepared by a person who did not have an access to competitors.

During the study, we also monitored the total calories, proteins, carbohydrates, and lipids consumed by the control and the experimental groups, stratified into breakfast, lunch, and supper.

\section{Data acquisition}

A fasting blood draw was completed to measure the following parameters: (1) creatine phosphokinase (CPK), (2) aspartate aminotransferase (AS), (3) alanine transaminase (ALT), (4) lactate dehydrogenase (LDH), (5) serum creatinine (SCr), (6) lactic acid (LH), (7) serum glucose (Gluc), (8) total blood protein (TBP), (9) corticosterone (C), (10) testosterone (T), and (11) blood urea nitrogen (BUN). All laboratory analyses were performed using the ARCHITECT ci8200 Integrated System, Abbott Diagnostic.

\section{Lactate profiling protocol}

The incremental $7 \times 200 \mathrm{~m}$ step test was used to provide objective information on the aerobic fitness of a swimmer. All testing was conducted in a $50 \mathrm{~m}$ pool. Individualized target times, based on the personal best time for each swimmer, were calculated before each test. The final swim was set to be for maximum effort. The time for each $100 \mathrm{~m}$ split and the total $200 \mathrm{~m}$ was recorded manually. After completion of each $200 \mathrm{~m}$, heart rate was measured with a Polar Sports Tester PE (Polar Electro Oy, Kempele, Finland) and a $25 \mathrm{~mL}$ capillary blood sample was taken from the earlobe or finger tip and analyzed for lactate concentration using the Accusport Blood Lactate Meter (Boehringer Mannheim, Germany). Lactate tolerance was assessed graphically on a plot of swimming velocity (swimming pace, $\mathrm{m} / \mathrm{s}$ over the distance of $200 \mathrm{~m}$ ) versus lactate concentration.

\section{Statistical analysis}

Changes induced by the training period in experimental and control groups were examined using the Wilcoxon signed-rank test. Differences between the groups were evaluated using the Wilcoxon rank sum test using the Pvalue of 0.05 as the statistical threshold. 
Relative changes induced by the experiment were measured using the "natural" relative difference, employing the natural logarithm, which was denoted as log percent (L\%) [11]: L\% $=100 * \ln$ (after/before).

\section{Results}

The basic statistics of the baseline and the experimental period are shown in Table 1.

An analysis of changes induced by SAA supplementation in experimental and control groups revealed the lack of statistically significant changes. However, the majority of changes observed in the experimental group are more pronounced than those observed in the control group.

A statistical comparison of the total calories, proteins, carbohydrates, and lipids consumed during the breakfast, lunch, and supper, revealed the lack of significant differences between the control and experimental group.

A concentration of serum lactic acid in the control group elevated (21.8 L\%), and decreased (-3.7 L\%) in experiment group.

Corticosterone concentration decreased in the control group $(-2.0 \% \mathrm{~L})$ while in the experimental group, it increased (10.9 L\%). Analogous, although not so pronounced, a decrease of $-6.1 \mathrm{~L} \%$ and an increase of $2.6 \mathrm{~L} \%$ of testosterone levels in the control and experimental groups was observed. It has to be noted that in the previous study an increase of only $1.3 \mathrm{~L} \%$ in mean testosterone levels after 44 days of exercise program was observed [7].

An increase of $47.7 \mathrm{~L} \%$ in the control group versus the lack of any changes in the experimental group was observed for ALT. AST concentration increased in both groups, and an increase in the control group was more pronounced than in the experimental group.

There was also a substantial increase in serum creatine kinase levels in both control and experimental groups.
An analysis of a lactate profile, Figure $1 \mathrm{~A}-\mathrm{B}$, as a function of a maximal swimming velocity, exposed a statistically significant positive shift of swimming velocity, at the reference of the lactate concentration of $4 \mathrm{mmol} / \mathrm{L}$, between the experimental group and the control group.

\section{Conclusions}

A search for novel supplements, other than anabolic steroids, lead to founding of a well-prospering industry, providing amateur and professional sportsmen with a vista of nutrition increasing muscular gain and stamina.

Among them, SAA has become very popular due to their supposed positive influence on physical stamina. Unfortunately, the popularity of this supplement is rendered rather by claims of a manufacturer and not lucid scientific reports on human models. To address this shortcomings we performed this study, which is the first ever attempt to analyze an impact of SAA supplementation on physical stamina in humans.

Taking into account the current literature on translation of drugs dose from animal to human [12], we primarily contemplated the use of $\sim 41 \mathrm{mg}$ of SAA per $\mathrm{kg}$ of body mass/day, not $500 \mathrm{mg} / \mathrm{kg} /$ day as presented in this study. However, we did not consider SAA as drugs, per se, but only as a nutritional supplement. Additionally a limited duration of an experiment i.e., 12-day training regime, and demands of team coaches inclined us to employ a very high dose of SAA. i.e., $500 \mathrm{mg} / \mathrm{kg}$ body mass/day.

In this study, performed on a group of competitive male swimmers, we confirmed the earlier finding, that indicated SAA induced increase in physical stamina; vide an increase of a maximal swimming velocity at the lactate threshold of $4 \mathrm{mmol} / \mathrm{L}[13,14]$ in the experimental group.

Table 1 Differences in physiological parameters at baseline and after 12-days training program in SAA supplemented group and a control group

\begin{tabular}{lllllll}
\hline Variable & Cont $(\mathbf{0})$ & Ex (0) & Cont (12) & Ex (12) & L\% Cont & L\% Ex \\
\hline LA & $0.82(0.76,0.9)$ & $1.1(0.98,1.1)$ & $1.02(0.92,1.15)$ & $1.06(0.905,1.2)$ & 21.8 & -3.7 \\
G & $94(92,101)$ & $90(90,93)$ & $80(74,81)$ & $85(80,87)$ & -16.1 & -5.7 \\
CPK & $195(168,215)$ & $168(113,368)$ & $290(288,297)$ & $413(331,568.5)$ & 39.7 & 89.9 \\
LDH & $310(272,314)$ & $298(266,310)$ & $389(303,391)$ & $339(305.5,398.5)$ & 22.7 & 12.9 \\
AST & $18(17,18)$ & $21(15,26)$ & $29(21,29)$ & $27(25,32.5)$ & 47.7 & 25.1 \\
TBP & $6.7(6.5,6.9)$ & $6.8(6.8,7)$ & $6.5(6.4,6.8)$ & $6.6(6.5,6.7)$ & -3.0 & -3.0 \\
ALT & $17(15,20)$ & $22(15,29)$ & $25.5(22.75,28.75)$ & $22(20.5,27)$ & 40.6 & 0 \\
SCr & $1.08(1.01,1.08)$ & $1.19(1.16,1.27)$ & $0.93(0.91,0.99)$ & $1.26(1.165,1.32)$ & -15.0 & 5.7 \\
BUN & $28(26,29)$ & $32(30,32)$ & $24(24,27)$ & $27(26,30)$ & -15.4 & -17.0 \\
C & $39.7(30.3,50.3)$ & $52.3(40.8,53)$ & $38.9(33.8,39.2)$ & $58.3(52.2,64.55)$ & -2.0 & 10.9 \\
T & $23.92(21.01,28.07)$ & $20.57(19.43,26.64)$ & $22.51(21.49,22.8)$ & $21.12(15.73,24.69)$ & -6.1 & 2.6 \\
\hline
\end{tabular}

Ex = experimental group; Cont = control group; LA = Lactic Acid $(\mathrm{mmol} / \mathrm{L}) ; \mathrm{G}=$ blood glucose $(\mathrm{mg} / \mathrm{dL}) ; \mathrm{CPK}=\mathrm{creatine}$ kinase $(\mathrm{U} / \mathrm{L}) ; \mathrm{LDH}=$ lactate dehydrogenase $(\mathrm{U} / \mathrm{L}) ; \mathrm{AST}=$ aspartate aminotransferase $(\mathrm{U} / \mathrm{L}) ; \mathrm{TBP}=$ Total Blood Protein $(\mathrm{g} / \mathrm{dL}) ; \mathrm{ALT}=$ alanine transaminase $(\mathrm{U} / \mathrm{L}) ; \mathrm{SCr}=\mathrm{Serum} \mathrm{creatinine}(\mathrm{mg} / \mathrm{dL}) ; \mathrm{BUN}=\mathrm{blood} \mathrm{urea}$ nitrogen $(\mathrm{mg} / \mathrm{dL}), \mathrm{C}=$ corticosterone $(\mathrm{nmol} / \mathrm{L}) ; \mathrm{T}=$ Testosterone $(\mathrm{nmol} / \mathrm{L})$. The values are presented as a median and an inter-quartile range. 

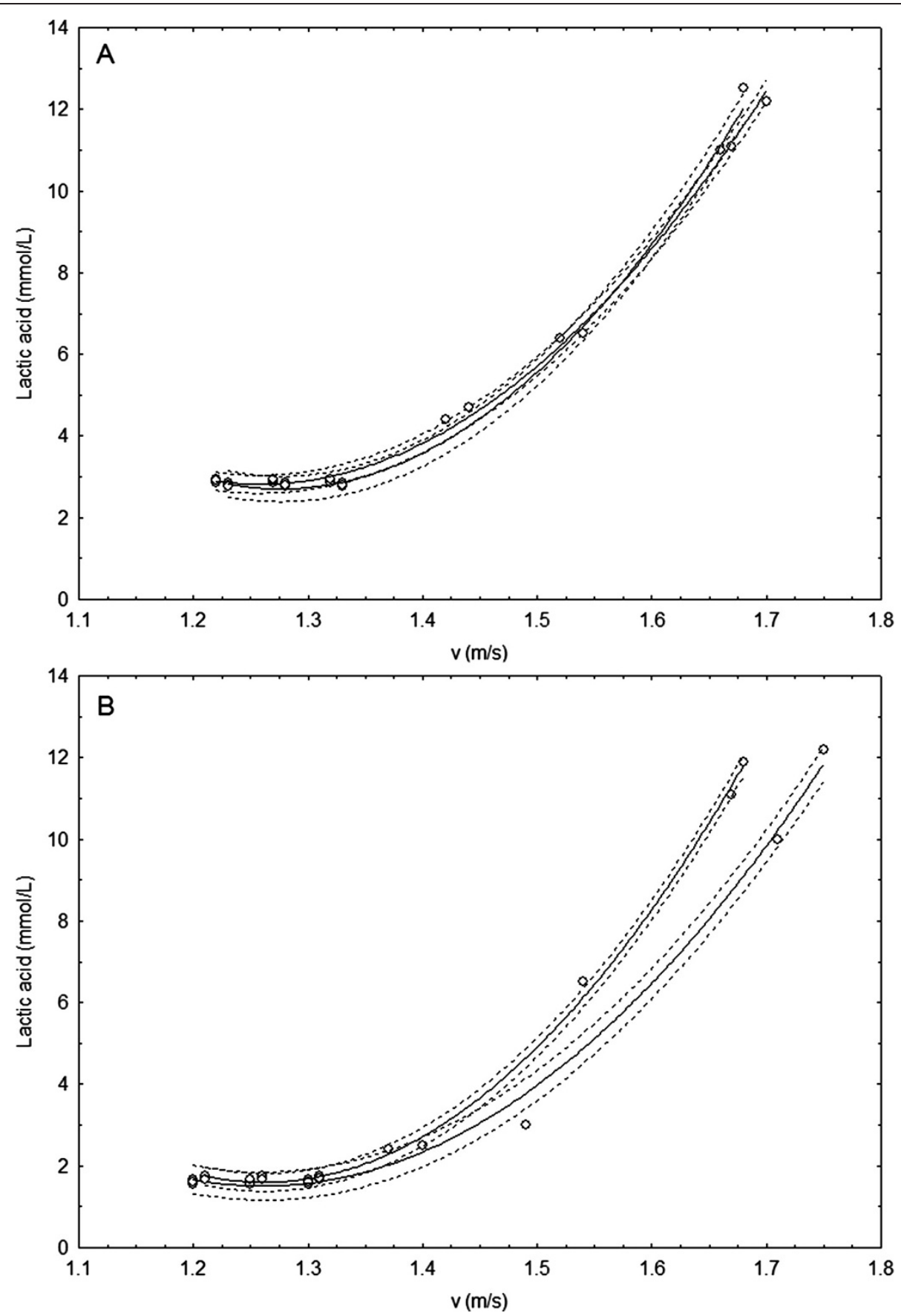

Figure 1 Blood Lactic Acid (mmol/L) concentration in the control group (A) and the experimental group (B) of elite male fin-swimmers athletes before and after 12 days training microcycle.

Although the previous study showed a positive influence of SAA supplementation on the elevation of testosterone levels on the $44^{\text {th }}$ day program, in which mice were administered to a weight-loaded ( $5 \%$ of body weight) forced swimming, this study, i.e., a 12-day SAA supplementation program combined with an extensive and rigorous training program, resulted only in an slight increase in serum testosterone levels.
There is a significant discrepancy regarding the levels of creatine phosphokinase (CPK), a marker of muscle damage, between this report and the previous one [7]. Opposite to the animal model study, this analysis shows a perspicacious increase in CPK levels in the experimental group as compared to the control group; a change of $36.7 \mathrm{~L} \%$ in the former versus $89.9 \mathrm{~L} \%$ in the latter. This observation allows us to conjecture that 
SAA supplementation induces a higher stamina, but it does not prevent a muscular damage caused by an extensive training effort. However, an analysis of the current literature indicated that supplementation with branchedchain amino acids and taurine-the supplement diminishing or preventing muscular damage caused by extensive training-may be the right direction for utilizing the whole potential of SAA supplementation [15].

The weak point of this study is small sample size, which may be responsible for the lack of more pronounced changes induced by SAA supplementation. Nevertheless, a comparison of our study's data with those performed on an animal model [7], where the study sample comprised only 10 animals, supported the practical viability of the obtained results.

\section{Competing interests}

The authors declare that they have no competing interests.

\section{Authors' contributions}

Significant manuscript writers: IZZ, SP, and MW. Concept and design: IZZ, ZO, and SP. Data analysis and interpretation: IZZ, AZ, and AC.

Statistical expertise: IZZ. All authors read and approved the final manuscript.

\section{Acknowledgements}

The authors gratefully acknowledge the financial support of the grant RSA2 05352.

\section{Author details}

${ }^{1}$ Jędrzej Śniadecki Academy of Physical Education and Sport ul, Kazimierza Górskiego 1, Gdańsk 80-336, Poland. ²Department of Microbiology and Biochemistry, University of Fort Hare, P/B X1314, Alice 5700, South Africa. ${ }^{3}$ School of Health and Applied Sciences, Polytechnic of Namibia, Private Bag 13388, 13 Storch Street, Windhoek, Namibia.

Received: 22 September 2014 Accepted: 7 November 2014

Published online: 30 November 2014

\section{References}

1. Kim J, Kyung J, Kim D, Choi EK, Bang P, Park D, Kim YB: Anti-obesity effects of Rapha $\operatorname{diet}(\mathrm{R})$ preparation in mice fed a high-fat diet. Lab Anim Res 2012, 28:265-271.

2. Zhaorigetu S, Yanaka N, Sasaki M, Watanabe H, Kato N: Silk protein, sericin, suppresses DMBA-TPA-induced mouse skin tumorigenesis by reducing oxidative stress, inflammatory responses and endogenous tumor promoter TNF-alpha. Oncol Rep 2003, 10:537-543.

3. Moore AJ, Devine DA, Bibby MC: Preliminary experimental anticancer activity of cecropins. Pept Res 1994, 7:265-269.

4. Sugiyama K, Mizuno M, Muramatsu K: Effect of individual amino acids on plasma cholesterol level in rats fed a high cholesterol diet. J Nutr Sci Vitaminol 1986, 32:623-633.

5. Gualano AB, Bozza T, Lopes De Campos P, Roschel H, Dos Santos Costa A Luiz Marquezi M, Benatti F, Herbert Lancha Junior A: Branched-chain amino acids supplementation enhances exercise capacity and lipid oxidation during endurance exercise after muscle glycogen depletion. J Sports Med Phys Fitness 2011, 51:82-88.

6. Shin S, Park D, Yeon S, Jeon JH, Kim TK, Joo SS, Lim WT, Lee JY, Kim YB: Stamina-enhancing effects of silk amino acid preparations in mice. Lab Anim Res 2009, 25:127-134.

7. Shin S, Yeon S, Park D, Oh J, Kang H, Kim S, Joo SS, Lim WT, Lee JY, Choi KC, Kim KY, Kim SU, Kim JC, Kim YB: Silk amino acids improve physical stamina and male reproductive function of mice. Biol Pharm Bull 2010, 33:273-278.

8. Rennie MJ: Influence of exercise on protein and amino acid metabolism. In Handbook of Physiology. Edited by Rowell LB, Shepherd JT. Bethesda, MD: American Physiological Society; 1996:995-1035.
9. Harris RC, Sale C: Beta-alanine supplementation in high-intensity exercise. Med Sport Sci 2012, 59:1-17.

10. Tipton KD: Role of protein and hydrolysates before exercise. Int J Sport Nutr Exerc Metab 2007, 17(Suppl):S77-86.

11. Tornqvist L, Vartia P, Vartia YO: How Should Relative Changes Be Measured. Am Stat 1985, 39:43-46.

12. Reagan-Shaw $S$, Nihal M, Ahmad N: Dose translation from animal to human studies revisited. FASEB J 2008, 22:659-661.

13. Sjodin B, Jacobs I: Onset of blood lactate accumulation and marathon running performance. Int J Sports Med 1981, 2:23-26.

14. Tanaka K, Matsuura Y, Kumagai S, Matsuzaka A, Hirakoba K, Asano K: Relationships of anaerobic threshold and onset of blood lactate accumulation with endurance performance. Eur J Appl Physiol Occup Physiol 1983, 52:51-56

15. Ra SG, Miyazaki T, Ishikura K, Nagayama H, Komine S, Nakata Y, Maeda S, Matsuzaki Y, Ohmori H: Combined effect of branched-chain amino acids and taurine supplementation on delayed onset muscle soreness and muscle damage in high-intensity eccentric exercise. J Int Soc Sports Nutr 2013, 10:51

doi:10.1186/s12970-014-0057-4

Cite this article as: Zubrzycki et al:: Supplementation with Silk Amino Acids improves physiological parameters defining stamina in elite finswimmers. Journal of the International Society of Sports Nutrition 2014 11:57

\section{Submit your next manuscript to BioMed Central and take full advantage of:}

- Convenient online submission

- Thorough peer review

- No space constraints or color figure charges

- Immediate publication on acceptance

- Inclusion in PubMed, CAS, Scopus and Google Scholar

- Research which is freely available for redistribution 